\title{
Risk factors associated with death in infants $<120$ days old with severe pertussis: a case-control study
}

\author{
Cong Liu' ${ }^{1,2,3}$, Lin Yang ${ }^{2,3,4}$, Yuwei Cheng ${ }^{2,3,4}$, Hongmei $X u^{1,2,3}$ and Feng $X u^{2,3,5^{*}}$
}

\begin{abstract}
Background and purpose: Pertussis is a serious infectious disease in young infants, and severe cases frequently cause death. Our study explored risk factors for death from severe pertussis.

Method: A case-control study of infants with severe pertussis admitted to the paediatric intensive care unit (PICU) in the Children's Hospital of Chongqing Medical University, China, from January 1, 2013, to June 30, 2019, was conducted. Pertussis was confirmed by clinical features and laboratory examinations. Severe pertussis was defined as patients with pertussis resulting in PICU admission or death. To understand the risk factors for death, we compared fatal and nonfatal cases of severe pertussis in infants aged $<120$ days by collecting clinical and laboratory data.

Results: The participants included 63 infants $<120$ days of age with severe pertussis. Fifteen fatal cases were confirmed and compared with 44 nonfatal severe pertussis cases, Four patients with termination of treatment were excluded. In the univariate analysis, the risk factors associated with death included apnoea $(P=0.001)$, leukocytosis (white blood cell (WBC) count $\geq 30 \times 10^{9} / \mathrm{L}(P=0.001)$ or $\left.\geq 50 \times 10^{9} / \mathrm{L}(P=0)\right)$, highest lymphocyte count $(P=0)$, pulmonary hypertension $(P=0.001)$, and length of PICU stay $(P=0.003)$. The multivariate analysis revealed that apnoea (OR $23.722,95 \% \mathrm{Cl} 2.796-$ 201.26, $P=0.004$ ), leukocytosis (OR 63.708,95\%Cl 3.574-1135.674, $P=0.005$ ) and pulmonary hypertension (OR 26.109, $95 \% \mathrm{Cl} 1.800-378.809, P=0.017$ ) were significantly associated with death.

Conclusion: Leukocytosis and pulmonary hypertension exhibited the greatest associations with death in infants with severe pertussis admitted to the PICU. Vaccination is still the most effective protection method against pertussis.
\end{abstract}

Keywords: Infant pertussis, Leukocytosis, Pulmonary hypertension, Acellular diphtheria, tetanus, and pertussis vaccine (DTaP)

\section{Introduction}

Pertussis is an acute respiratory infection caused by Bordetella pertussis and is characterized by paroxysmal coughing, coughing ending in a whooping sound, vomiting, apnoea or cyanosis [1]. The World Health Organization (WHO) estimated that 151,074 pertussis cases occurred in 2018 and 89,000 pertussis deaths

\footnotetext{
* Correspondence: xufeng9899@163.com

${ }^{2}$ National Clinical Research Center for Child Health and Disorders, Ministry of Education Key Laboratory of Child Development and Disorders, Chongqing 400014, China

${ }^{3}$ Chongqing Key Laboratory of Pediatrics, Chongqing 400014, China

Full list of author information is available at the end of the article
}

occurred in 2008 (http://www.who.int/ith/diseases/pertussis/en/). However, even after widespread vaccination with the $\mathrm{DTaP}$, reported pertussis cases substantially increased and are still increasing in China. The current programme for pertussis vaccination in China is administration of 1 dose at 3, 4, and 5 months of age and 1 increased dose at 18-24 months of age. At present, there is no programme for pertussis immunization during pregnancy $[2,3]$. According to the Chinese Center for Disease Control and Prevention, 32,452 cases of pertussis were reported in 2011-2017, with an annual incidence 0.34 per 100,000 individuals; $60 \%$ of cases were in

C C The Author(s). 2020 Open Access This article is licensed under a Creative Commons Attribution 4.0 International License, which permits use, sharing, adaptation, distribution and reproduction in any medium or format, as long as you give appropriate credit to the original author(s) and the source, provide a link to the Creative Commons licence, and indicate if changes were made. The images or other third party material in this article are included in the article's Creative Commons licence, unless indicated otherwise in a credit line to the material. If material is not included in the article's Creative Commons licence and your intended use is not permitted by statutory regulation or exceeds the permitted use, you will need to obtain permission directly from the copyright holder. To view a copy of this licence, visit http://creativecommons.org/licenses/by/4.0/ The Creative Commons Public Domain Dedication waiver (http://creativecommons.org/publicdomain/zero/1.0/) applies to the data made available in this article, unless otherwise stated in a credit line to the data. 
infants $\leq 5$ months old. Hence, pertussis remains a serious disease in China, particularly in those too young to have completed their vaccination course. However, data on severe pertussis and death due to pertussis in China are scarce. Chongqing, a city in Western China, is among the top five cities with the highest pertussis prevalence [3]. To elucidate the status of severe pertussis in Chongqing, we collected data from January 2013 to July 2019 at the Children's Hospital of Chongqing Medical University. The numbers of severe pertussis cases and deaths in $<120$ day-old infants are shown in Fig. 1; both cases and deaths increased annually between 2016 and 2019. To gain further insight into the characteristics and treatment of severe pertussis and to determine the most important risk factors associated with death, we analysed data from < 120-day-old infants with severe pertussis.

\section{Methods}

\section{Cases and controls}

This was a case-control study of paediatric pertussis patients admitted to the PICU at the Children's Hospital of Chongqing Medical University, China, from January 1, 2013 to June 30, 2019. The clinical features of pertussis included increasing frequency and severity of cough ending in a whooping sound or vomiting, apnoea or cyanosis. Some newborns had only cyanosis without cough. All cases were confirmed by isolation of $B$. pertussis by culture or detection of $B$. pertussis DNA by polymerase chain reaction (PCR) assays. Severe pertussis was defined as patients with pertussis resulting in PICU admission. The case group was defined as pertussis patients admitted to the PICU and dying from pertussis disease. The control group included pertussis patients admitted to the PICU and surviving pertussis disease.

\section{Medical record review}

Hospital medical records were obtained, and data on birth factors; vaccination history; symptoms; course of illness; comorbidities; treatment including exchange transfusion (ET) or extracorporeal membrane oxygenation (ECMO); type of respiratory support; patient outcome; microbiology test results, such as full blood count; chest imaging reports by radiologists; and echocardiography findings were recorded. The birth weight and gestational age were obtained from birth records. Vaccination status was collected from the medical record or a copy of the vaccination record. Fever was defined as a tympanic or axillary temperature above $38^{\circ} \mathrm{C}$. The course of illness included the cough duration before hospitalization, PICU admission and the length of hospital and PICU stay, which were collected from the medical records. Pneumonia was defined by chest imaging. The highest white blood cell (WBC) count, platelet count, and lymphocyte count were recorded and analysed. Leucocytosis was defined as a WBC count $\geq 30 \times 10^{9} / \mathrm{L}$.

\section{Statistical analysis}

SPSS v 23.0 software was used for the statistical analysis. The basic information and clinical characteristics of the two groups were compared by chi-square tests for categorical variables and Student's t-tests or Mann Whitney $\mathrm{U}$ tests for continuous variables. For normally distributed continuous variables, Student's t-test was used for comparisons; otherwise, a Mann Whitney U test was used. Univariate logistic regression analysis was performed to identify factors associated with death among infants with pertussis disease requiring admission to the PICU. Backward elimination stepwise multivariable logistic regression models were developed to identify independent risk factors for death among infants with

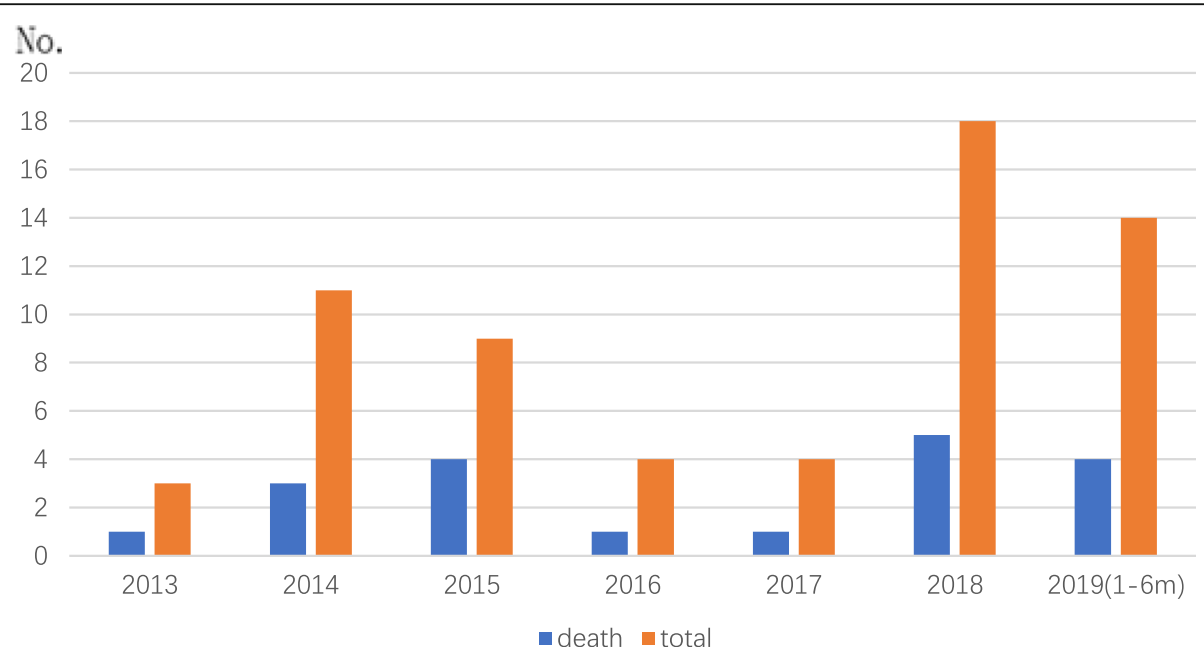

Fig. 1 The number of pertussis cases needing PICU admission and number of deaths, Children's Hospital of Chongqing Medical University, China; January 1, 2013- June 30, 2019 
pertussis disease requiring admission to the PICU. Th Pto-remove value was set as a $c>0.05$. Variables with a $P$ value of $<0.05$ were included in the final regression model. All $P$ values $<0.05$ were considered statistically significant for all tests.

\section{Results}

From January 1, 2013 to June 30, 2019, 3280 pertussis patients were admitted to the Children's Hospital of Chongqing Medical University, and 89 patients with severe pertussis were admitted to the PICU, including 63 patients who were $<120$ days old. The 63 patients included 1 patient aged $\leq 1$ month, 31 patients (49.2\%) aged 1-2 months, 24 patients (38\%) aged 2-3 months, and 7 patients $(11.1 \%)$ aged $3-4$ months, and the average age of cough onset was $<3$ months. For 5 patients, treatment was terminated by their parents because the condition too serious to survive, and their parents were unable to accept the bad consequences. Among those who stopped receiving treatment, 4 patients died and 1 patient survived according to telephone follow-up. The 4 patients who died were excluded, and 59 cases were included in our study. The basic information, clinical symptoms and vaccination history of the patients are presented in Table 1.

Fifteen of the 59 patients died (25.4\%). We divided the patients into two groups: the fatal group $(n=15)$ and nonfatal group $(n=44)$. Thirty-two $(54.2 \%)$ infants were male, including 6 in the fatal group and 26 in the nonfatal group. The average weight was $5.13 \pm 1.12 \mathrm{~kg}$ in the fatal group and $5.27 \pm 1.07 \mathrm{~kg}$ in the nonfatal group. There were no differences in prematurity,birth weight and month age between two groups. The vaccination acceptance rate was generally low in our study, as the onset age for all the patients in our study was less than 3 months; the vaccination rate was $3.3 \%$, and only 2 infants had received 1 dose of the vaccine in the fatal group. Almost all (57/59) infants had cough and cyanosis. Only 2 patients had only cyanosis without coughing which one was newborn.

The clinical manifestations of pertussis, main laboratory indexes, complications and treatments are presented in Table 2 . The majority of infants $(n=49)$ received echocardiograms, and congenital heart disease (CHD) $(n=20)$ and pulmonary hypertension $(n=11)$ were present in some infants. Although some patients had CHD, such as an atrial septal defect (ASD, $n=18$ ), or patent ductus arteriosus (PDA, $n=2$ ) without complex CHD or cardiac dysfunction, the rate of CHD was not significantly different between the fatal and nonfatal groups. Five patients in the fatal group and 3 patients in the nonfatal group had CHD and pulmonary hypertension. All 8 patients had an ASD. In addition to CHD, 16 patients had other comorbidities including bronchopulmonary dysplasia $(n=4)$,

Table 1 Basic information, clinical symptoms and vaccination history of the death group and nondeath group

\begin{tabular}{|c|c|c|c|c|c|}
\hline \multirow[t]{2}{*}{ Characteristic } & \multicolumn{2}{|l|}{ Deaths $(n=15)$} & \multicolumn{2}{|c|}{ Nondeaths $(n=44)$} & \multirow[b]{2}{*}{$P$ Value } \\
\hline & NO. of Patients & NO.(\%) & NO. of Patients & NO.(\%) & \\
\hline \multicolumn{6}{|l|}{ age } \\
\hline$\leq 1$ month & 1 & $6.67 \%$ & 1 & $2.27 \%$ & 0.417 \\
\hline $1-2$ month & 6 & $40 \%$ & 19 & $43.18 \%$ & 0.829 \\
\hline $2-3$ month & 4 & $26.67 \%$ & 13 & $29.55 \%$ & 0.832 \\
\hline 3-4 month & 4 & $26.67 \%$ & 11 & $25.00 \%$ & 0.898 \\
\hline Male sex & 6 & & 26 & & 0.2 \\
\hline weight (kg) & & $5.13 \pm 1.12$ & & $5.27 \pm 1.07$ & 0.135 \\
\hline premature & 4 & $26.67 \%$ & 6 & $13.64 \%$ & 0.245 \\
\hline Birth weight (kg) & & $2.96 \pm 4.41$ & & $3.17 \pm 5.07$ & 0.149 \\
\hline Vaccination history & 2 (1 dose) & & 0 & & \\
\hline \multicolumn{6}{|l|}{ symptoms } \\
\hline fever & 9 & $60.00 \%$ & 19 & $43.18 \%$ & 0.26 \\
\hline paroxysmal coughing & 14 & $93.33 \%$ & 43 & $97.70 \%$ & 0.417 \\
\hline whoop & 11 & $73.30 \%$ & 23 & $52.30 \%$ & 0.154 \\
\hline apnoea & 12 & $80.00 \%$ & 14 & $31.80 \%$ & 0.001 \\
\hline cyanosis & 15 & $100 \%$ & 44 & $100 \%$ & \\
\hline Laboratory confirmed & 15 & $100 \%$ & 44 & $100 \%$ & \\
\hline
\end{tabular}

Prematurity was defined as birth at $<37$ weeks' gestation Only 2 infants had received 1 dose of the vaccine (DTaP) in the death group Fever was defined as a tympanic or axillary temperature $>38^{\circ} \mathrm{C}$ 
Table 2 Course of illness, main laboratory indexes and treatment of the death group and nondeath group

\begin{tabular}{|c|c|c|c|c|c|}
\hline \multirow[t]{2}{*}{ Characteristic } & \multicolumn{2}{|l|}{ Deaths $(n=15)$} & \multicolumn{2}{|c|}{ Nondeaths $(n=44)$} & \multirow[b]{2}{*}{$P$ Value } \\
\hline & NO. of Patients & NO. (\%) & NO. of Patients & NO. (\%) & \\
\hline \multicolumn{6}{|l|}{ Course of illness } \\
\hline length of hospital stay (IQR) & & $10(3-15)$ & & $25.5(19.25-31.75)$ & 0 \\
\hline Cough duration before the PICU (IQR) & & $11(7-14)$ & & $14(8-19.75)$ & 0.061 \\
\hline length of PICU stay (IQR) & & $3(2-12)$ & & $13.5(8-17)$ & 0.003 \\
\hline Leukocytosis (WBC $\geq 30 \times 10^{9} / \mathrm{L}$.) & 14 & $93.33 \%$ & 19 & $43.18 \%$ & 0.001 \\
\hline Leukocytosis (WBC $\geq 50 \times 10^{9} / \mathrm{L}$.) & 13 & $86.67 \%$ & 7 & $15.91 \%$ & 0 \\
\hline Highest WBC count & & $77.33 \pm 28.56$ & & $30.52 \pm 16.46$ & 0 \\
\hline Highest lymphocyte count & & $29.59 \pm 13.59$ & & $16.19 \pm 9.20$ & 0 \\
\hline Highest Platelet count & & $740.47 \pm 199.93$ & & $696.05 \pm 153.47$ & 0.375 \\
\hline Congenital heart disease (ASD or PDA) & $5(13)$ & $38.46 \%$ & $15(36)$ & $41.66 \%$ & 1 \\
\hline Pulmonary hypertension & $8(14)$ & $57.14 \%$ & $3(36)$ & $8.33 \%$ & 0.001 \\
\hline Pulmonary hypertension without CHD & $3(8)$ & $44.40 \%$ & $0(3)$ & 0 & 0.214 \\
\hline Pneumonia & 15 & $100 \%$ & 44 & $100 \%$ & \\
\hline Co-infectious with clearly pathogen & 13 & $86.60 \%$ & 38 & $86.36 \%$ & 0.976 \\
\hline Consolidation of lung & 9 & $60.00 \%$ & 23 & $52.27 \%$ & 0.604 \\
\hline Convulsions & 2 & $13.30 \%$ & 8 & $18.20 \%$ & 0.666 \\
\hline Pertussis encephalopathy & 5 & $33.30 \%$ & 21 & $47.70 \%$ & 0.332 \\
\hline Co- morbidity & 12 & $80.00 \%$ & 24 & $54.54 \%$ & 0.081 \\
\hline \multicolumn{6}{|l|}{ Treatment } \\
\hline Received macrolide antibiotics & 15 & $100 \%$ & 44 & $100 \%$ & \\
\hline Days to macrolide initiation (IQR) & & $8(6-11)$ & & $10.5(9-15)$ & 0.012 \\
\hline Received steroids & 6 & $40.00 \%$ & 13 & $29.50 \%$ & 0.454 \\
\hline Respiratory support (invasive or/and noninvasive) & 15 & $100 \%$ & $36+4$ & $90.90 \%$ & 0.226 \\
\hline intubated & 15 & $100 \%$ & 36 & $81.80 \%$ & 0.076 \\
\hline Ventilator time & & $3(2-12)$ & & $8(5-13.75)$ & 0.412 \\
\hline Exchange transfusion & 3 & $20.00 \%$ & 2 & $4.55 \%$ & 0.063 \\
\hline ECMO & 1 & $0.07 \%$ & 0 & & 0.084 \\
\hline
\end{tabular}

Abbreviations: IQR interquartile range, $C H D$ congenital heart disease, ECMO extracorporeal membrane oxygenation, $A S D$ atrial septal defect, PDA patent ductus arteriosus

Leukocytosis was defined as WBC count $\geq 30 \times 10^{9} / \mathrm{L}$

Co-morbidity included CHD, bronchopulmonary dysplasia, hypoxic ischaemic encephalopathy, rotavirus enteritis, Down syndrome, hypoplasia of the laryngeal cartilage, adenovirus encephalitis, and epilepsy

hypoxic ischaemic encephalopathy $(n=4)$, rotavirus enteritis $(n=4)$, Down syndrome $(n=1)$, hypoplasia of the laryngeal cartilage, adenovirus encephalitis, and epilepsy. Although the majority of patients had more than one comorbidity, none of the comorbidities were the main cause of death in our study.

All patients underwent chest imaging, and pneumonia and respiratory pathogens were detected by culture and PCR assays performed on sputum; serological examination was performed supplementally. Fifty-one patients (86\%) had coinfections with clear pathogeny on admission; coinfections included respiratory syncytial virus (RSV) $(n=13)$, Klebsiella pneumoniae $(n=13)$, Haemophilus influenzae $(n=13)$, adenovirus $(n=3)$, and influenza B $(n=3)$. The majority of patients had more than one pathogen infection. However, the rates of coinfection with specific pathogens were not significantly different between the fatal and nonfatal groups.

During treatment, all the patients received macrolides. In the nonfatal group, 40 patients $(90 \%)$ required respiratory support (36 were intubated and 4 required noninvasive ventilation). All fatal cases required intubation. Five patients were treated with ETs, and 3 died. The peak WBC count in patients in the fatal group with ET ranged from $70.44 \times 10^{9} / \mathrm{L}$ to $84.93 \times 10^{9} / \mathrm{L}$. The peak WBC count in patients in the nonfatal group with ET ranged from $56.44 \times 10^{9} / \mathrm{L}$ to $59.95 \times 10^{9} / \mathrm{L}$. All patients in the fatal group with ET experienced shock and 
respiratory failure, and 1 infant had multiorgan failure prior to the ET procedure. Two infants underwent ET twice to decrease the leukocyte count but subsequently died.

Only 1 patient in the fatal group received ECMO for 2 days and received respiratory support and haemodialysis (for renal insufficiency) at the same time. The infant's WBC count was $97.22 \times 10^{9} / \mathrm{L}$ on admission and peaked at $135.58 \times 10^{9} / \mathrm{L}$. The case was complicated with pulmonary hypertension, acute respiratory distress syndrome (ARDS), and multiorgan failure prior to the ECMO procedure. Finally, pulmonary haemorrhage and brain hernia occurred, and the patient died soon after.

The univariate analysis of risk factors related to death is shown in Table 3. According to the univariate analysis, the risk factors associated with death were apnoea $(P=$ $0.001)$, highest lymphocytosis count $(P=0)$, WBC counts $\geq 30 \times 10^{9} / \mathrm{L}(P=0.001)$ and $\geq 50 \times 10^{9} / \mathrm{L}(P=0)$, pulmonary hypertension $(P=0.001)$, and length of PICU stay (days) $(P=0.003)$. The multivariate analysis of risk factors related to death is shown in Table 4. Apnoea (OR 23.722, 95\%CI 2.796-201.26, $P=0.004$ ), leukocytosis (OR 63.708, 95\%CI 3.574-1135.674, $P=0.005)$ and pulmonary hypertension (OR 26.109, 95\%CI 1.800-378.809, $P=0.017$ ) were significantly associated with death. WBC counts $\geq 30 \times 10^{9} / \mathrm{L}$ or $\geq 50 \times 10^{9} / \mathrm{L}$ and pulmonary hypertension were significantly associated with death.

\section{Discussion}

Pertussis resurgence has been observed in recent years, and severe pertussis and death due to pertussis have gradually increased. According to other research, age $\leq 3$ months is a risk factor for severe and death in pertussis cases [4-9], and $78.8 \%(63 / 89)$ of severe pertussis patients were aged $\leq 3$ months in our hospital; this result is consistent with other studies. Our findings were consistent in 59 patients with severe pertussis who had a cough onset age of $<3$ months after excluding 4 patients for whom treatment was terminated and who later died. Our study analysed 15 fatal pertussis cases and 44 nonfatal pertussis cases. In the study by Winter et al.,

Table 3 Univariate logistic regression analysis of severe pertussis associated with death

\begin{tabular}{llc}
\hline characteristic & $\boldsymbol{P}$ Value & unadjusted OR(95\%Cl) \\
\hline apnoea & 0.001 & $8.571(2.082-35.294)$ \\
length of PICU stay (IQR) & 0.003 & \\
Leukocytosis $\left(\mathrm{WBC} \geq 30 \times 10^{9} / \mathrm{L}.\right)$ & 0.001 & $18.421(2.223-152.647)$ \\
Leukocytosis (WBC $\left.\geq 50 \times 10^{9} / \mathrm{L}.\right)$ & 0 & $34.357(6.316-186.900)$ \\
Highest WBC count & 0 & \\
Highest lymphocyte count & 0 & \\
Pulmonary hypertension & 0.001 & $14.667(3.001-71.678)$ \\
\hline
\end{tabular}

Abbreviations: IQR interquartile range, $O R$ odds ratio; $\mathrm{Cl}$, confidence interval Leukocytosis was defined as WBC count $\geq 30 \times 10^{9} / \mathrm{L}$
Table 4 Multivariate logistic regression analysis of severe pertussis associated with death

\begin{tabular}{llll}
\hline & adjusted OR & $\mathbf{9 5 \% C l}$ & $\boldsymbol{P}$ Value \\
\hline apnea & 23.722 & $2.796-201.260$ & 0.004 \\
Leukocytosis & 63.708 & $3.574-1135.674$ & 0.005 \\
Pulmonary hypertension & 26.109 & $1.800-378.809$ & 0.017 \\
\hline
\end{tabular}

Abbreviations: $\mathrm{Cl}$ confidence interval, $O R$ odds ratio

Leukocytosis was defined as WBC count $\geq 30 \times 10^{9} / \mathrm{L}$

patients with fatal outcomes had a younger gestational age and lower birth weight than those with nonfatal outcomes [10]. The study by Abu-Raya et al. found age of < 4 weeks, prematurity, and female sex were independent risk factors for death [11].

We found that apnoea, leukocytosis, and pulmonary hypertension were significantly associated with death in severe pertussis cases. Currently, in severe pertussis cases, leukocytosis and lymphocytosis are commonly observed and are significantly correlated with death $[6,10,12-15]$. Pertussis toxin (PT) indirectly leads to the development of pulmonary hypertension through the induction of lymphocytosis (leukocytosis). The aggregation of leukocytes in pulmonary arterioles, veins and the lymphatic system was observed in the lungs of pertussis-infected infants after death [16-18]. In our study, leukocytosis was significantly associated with death, similar to the results of other publications. Only 2 patients with fatal outcomes did not present leukocytosis in our study. One patient had comorbid trisomy 21 syndrome with an ASD and a maximum WBC count of $16.58 \times 10^{9} / \mathrm{L}$. This infant was coinfected with RSV and diagnosed with severe pneumonia and ARDS. The second infant was admitted after cardiopulmonary resuscitation due to asphyxia. Pertussis was diagnosed after admission. The maximum WBC count was $23.19 \times 10^{9} / \mathrm{L}$. It is possible that asphyxia and leukocytosis were significantly related to pertussis infection. Both patients died of respiratory failure without pulmonary hypertension.

Of greatest importance in the treatment of pertussis is the administration of a macrolide antibiotic. PICU management of infant pertussis cases has been limited [17, 19, 20]. Extreme leukocytosis with lymphocytosis is associated with infant death [10]. Pertussis toxin (PT)-promoted leukocytosis and indirect development of pulmonary hypertension are the most important risk factors related to death in patients with severe pertussis. Could death be reduced by rapidly reducing leukocytes and lymphocytes in patients with severe pertussis? In 2004, Romano et al. published the first report on ET in a patient with severe pertussis [21]; thereafter, ET has been reported in multiple case reports of severe pertussis treatment [22-28]. According to previous research, although there is a lack of a unified standard, ET showed potential therapeutic benefits and promising results and is worthy of future exploration [18, 21, 25, 27, 29]. In 
our study, 5 patients were treated with ET, of whom 3 died. The peak WBC count of patients in the fatal group who underwent ET was significantly higher than that in the nonfatal group. Although there was no significant difference between the two groups treated with ET, the variations may be related to the time of treatment onset and the severity of illness; however, this needs to be confirmed by additional standardized control studies in the future. ECMO has a long history of use in the treatment of severe pertussis in young infants, but there is no consensus on its efficacy; however, it has been shown to have some clinical benefits [26, 27, 30-32]. In our research, ECMO was performed in only 1 patient in the fatal group. We observed no significant difference between the two groups treated with ECMO and ET, likely because these treatments were initiated only when the disease became life-threatening; however, these treatments still might play a potential role in severe pertussis.

To date, the main preventive strategy for pertussis in China is a vaccination scheme with three doses starting at 3 months of age. According to previous reports, most patients with fatal outcomes were too young to receive their first dose of the DTaP vaccine [10]. In our study, the majority of our infants were $<3$ months of age, but 2 patients received one dose of the pertussis vaccine. Although the two patients were vaccinated, they began to cough before vaccination, and pertussis infection was considered. For this reason, many countries have already recommended that the initial vaccination scheme should start at 6 weeks of age. Since 2011, many countries have vaccinated pregnant women between 27 and 36 weeks gestation with the DTaP vaccine to prevent infection and death in infants $\leq 2$ months old [33-38]. The DTaP vaccine has shown no adverse effects on the pregnancy or the foetus [39-41]. Therefore, our national vaccination schedule may need to be changed to protect an increased number of infants.

Because this is a retrospective study, it has some limitations, including a limited number of cases. All the patients in our study had varying degrees of hypoxemia and required respiratory support (59 invasive and 4 noninvasive); thus, their conditions were very serious, and a high mortality rate was observed, which explains why we had a limited number of cases. In addition, 10 infants did not undergo echocardiography, and heart and pulmonary artery conditions were unknown. Meanwhile, we could not collect the smoking habits of patients' parents to determine whether any connection existed between pertussis and smoking.

\section{Conclusion}

Throughout history, most pertussis deaths have occurred in infants. Leukocytosis and pulmonary hypertension are the greatest risk factors for death in infants with severe pertussis. Currently, the treatment of severe pertussis is limited and should be improved. ET and ECMO are also worth exploring as treatments, but additional data are needed. Vaccination is still the most effective protection method. Considering that $\leq 3$ months of age is a risk factor for severe pertussis, our national vaccination schedule needs to be changed to protect infants in this age group.

\begin{abstract}
Abbreviations
PICU: Paediatric intensive care unit; DTaP: Acellular diphtheria, tetanus, and pertussis vaccine; WHO: World Health Organization; PCR: Polymerase chain reaction; ET: Exchange transfusion; ECMO: Extracorporeal membrane oxygenation; WBC: White blood cell; CHD: Congenital heart disease; ASD: Atrial septal defect; PDA: Patent ductus arteriosus; IQR: Interquartile range; OR: Odds ratio; Cl: Confidence interval; RSV: Respiratory syncytial virus; ARDS: Acute respiratory distress syndrome; PT: Pertussis toxin
\end{abstract}

\section{Acknowledgements}

Valuable thanks will be extended to the Department of Infectious Diseases and PICU, Children's Hospital of Chongqing Medical University for providing clinical cases. We thank the Department of Epidemiology for providing statistical guidance. We also thank all the partcipants for their help.

\section{Authors' contributions}

$\mathrm{CL}$ conducted concepts, design, data collection and analysis, and drafted the manuscript. LY and YWC conducted data collection. HMX performed statistical analysis. FX as corresponding author conceived the study, participated in its design and coordination, and helped draft the manuscript. All authors approved the submission of the final manuscript.

\section{Funding}

No fund supports.

\section{Availability of data and materials}

The datasets generated and/or analyzed during the current study are not publicly available due to participant privacy but are available from the corresponding author on reasonable request.

\section{Ethics approval and consent to participate}

This study was approved by the Ethics Regional Committee of Children's Hospital Affiliated to Chongqing Medical University (File No. (2020)13) and the requirement for informed consent was waived due to the retrospective design of the study. The collected data was anonymized before its use.

\section{Consent for publication}

Not applicable.

\section{Competing interests}

The authors declare that they have no competing interests.

\section{Author details \\ ${ }^{1}$ Department of Infectious Diseases, Children's Hospital of Chongqing Medical University, Chongqing 400014, China. ${ }^{2}$ National Clinical Research Center for Child Health and Disorders, Ministry of Education Key Laboratory of Child Development and Disorders, Chongqing 400014, China. ${ }^{3}$ Chongqing Key Laboratory of Pediatrics, Chongqing 400014, China. ${ }^{4}$ Department of Emergency, Children's Hospital of Chongqing Medical University, Chongqing 400014, China. ${ }^{5}$ Department of Pediatric Intensive Care Unit, Children's Hospital of Chongqing Medical University, Chongqing 400014, China.}

Received: 18 March 2020 Accepted: 21 October 2020 Published online: 16 November 2020

\section{References}

1. Halperin SA, Vaudry W, Boucher FD, Mackintosh K, Waggener TB, Smith B, Pediatric Investigators Collaborative Network on Infections in C. Is pertussis immune globulin efficacious for the treatment of hospitalized infants with pertussis? No answer yet. Pediatr Infect Dis J. 2007;26(1):79-81. 
2. Wang Z, Ma C, Yan Y. Global pertussis resurgence and the status of related pertussis researches in China. Zhongguo Yi Miao He Mian Yi. 2016;22(03): 345-9.

3. Ning G, Gao Y, Wu D, Li J, Li Y, Shao Z, al. e: Epidemiology of pertussis in China 2011-2017 Zhongguo Yi Miao He Mian Yi 2018, 24:264-267.

4. Kaczmarek MC, Schlebusch S, Ware RS, Coulthard MG, McEniery JA, Lambert SB. Diagnostic testing in influenza and pertussis related paediatric intensive care unit admissions, Queensland, Australia, 1997-2013. Commun Dis Intell Q Rep. 2017;41(4):E308-e317.

5. Straney L, Schibler A, Ganeshalingham A, Alexander J, Festa M, Slater A, MacLaren G, Schlapbach LJ. Burden and outcomes of severe pertussis infection in critically ill infants. Pediatr Crit Care Med. 2016;17(8):735-42.

6. Jordan I, Felipe A, Balaguer M, Esteban E, Tello R, Cambra FJ, Villanova M, Esteban ME. Morbidity and mortality risk factors of pertussis in pediatrics. J Inf Secur. 2017;74(1):97-100.

7. Skowronski DM, Janjua NZ, Tsafack EP, Ouakki M, Hoang L, De Serres G. The number needed to vaccinate to prevent infant pertussis hospitalization and death through parent cocoon immunization. Clin Infect Dis. 2012;54(3):31827.

8. Halperin SA, Wang EE, Law B, Mills E, Morris R, Dery P, Lebel M, MacDonald N, Jadavji T, Vaudry W, et al. Epidemiological features of pertussis in hospitalized patients in Canada, 1991-1997: report of the immunization monitoring program--active (IMPACT). Clin Infect Dis. 1999;28(6):1238-43.

9. Bettinger JA, Halperin SA, De Serres G, Scheifele DW, Tam T. The effect of changing from whole-cell to acellular pertussis vaccine on the epidemiology of hospitalized children with pertussis in Canada. Pediatr Infect Dis J. 2007;26(1):31-5.

10. Winter K, Zipprich J, Harriman K, Murray EL, Gornbein J, Hammer SJ, Yeganeh N, Adachi K, Cherry JD. Risk factors associated with infant deaths from pertussis: a case-control study. Clin Infect Dis. 2015;61(7):1099-106.

11. Abu-Raya B, Bettinger JA, Vanderkooi OG, Vaudry W, Halperin SA, Sadarangani M. Burden of children hospitalized with pertussis in Canada in the Acellular pertussis vaccine era, 1999-2015. J Pediatric Infect Dis Soc. 2020;9(2):118-27.

12. Mikelova LK, Halperin SA, Scheifele D, Smith B, Ford-Jones E, Vaudry W, Jadavji T, Law B, Moore D. Predictors of death in infants hospitalized with pertussis: a case-control study of 16 pertussis deaths in Canada. J Pediatr. 2003;143(5):576-81.

13. Wortis N, Strebel PM, Wharton M, Bardenheier B, Hardy IR. Pertussis deaths: report of 23 cases in the United States, 1992 and 1993. Pediatrics. 1996; 97(5):607-12.

14. Haberling DL, Holman RC, Paddock CD, Murphy TV. Infant and maternal risk factors for pertussis-related infant mortality in the United States, 1999 to 2004. Pediatr Infect Dis J. 2009;28(3):194-8

15. Murray EL, Nieves D, Bradley JS, Gargas J, Mason WH, Lehman D, Harriman $K$, Cherry JD. Characteristics of severe Bordetella pertussis infection among infants $</=90$ days of age admitted to pediatric intensive care units Southern California, September 2009-June 2011. J Pediatric Infect Dis Soc. 2013;2(1):1-6.

16. Mattoo S, Cherry JD. Molecular pathogenesis, epidemiology, and clinical manifestations of respiratory infections due to Bordetella pertussis and other Bordetella subspecies. Clin Microbiol Rev. 2005;18(2):326-82.

17. Cherry JD, Paddock CD. Pathogenesis and histopathology of pertussis: implications for immunization. Expert Rev Vaccines. 2014;13(9):1115-23.

18. Nieves D, Bradley JS, Gargas J, Mason WH, Lehman D, Lehman SM, Murray EL, Harriman K, Cherry JD. Exchange blood transfusion in the management of severe pertussis in young infants. Pediatr Infect Dis J. 2013;32(6):698-9.

19. Cherry JD. Pertussis in young infants throughout the world. Clin Infect Dis. 2016;63(suppl 4):S119-s122.

20. Cherry JD. Pertussis: challenges today and for the future. PLoS Pathog. 2013; 9(7):e1003418

21. Romano MJ, Weber MD, Weisse ME, Siu BL. Pertussis pneumonia, hypoxemia, hyperleukocytosis, and pulmonary hypertension: improvement in oxygenation after a double volume exchange transfusion. Pediatrics. 2004;114(2):e264-6.

22. Tian SF, Wang HM, Deng JK. Fatal malignant pertussis with hyperleukocytosis in a Chinese infant: a case report and literature review. Medicine (Baltimore). 2018;97(17):e0549.

23. Onoro G, Salido AG, Martinez IM, Cabeza B, Gillen M, de Azagra AM. Leukoreduction in patients with severe pertussis with hyperleukocytosis. Pediatr Infect Dis J. 2012;31(8):873-6.
24. Cherry JD, Wendorf K, Bregman B, Lehman D, Nieves D, Bradley JS, Mason WH, Sande-Lopez L, Lopez M, Federman M, et al. An observational study of severe pertussis in 100 infants $</=120$ days of age. Pediatr Infect Dis J. 2018; 37(3):202-5.

25. Donoso AF, Cruces PI, Camacho JF, Leon JA, Kong JA. Exchange transfusion to reverse severe pertussis-induced cardiogenic shock. Pediatr Infect Dis J. 2006;25(9):846-8.

26. Sawal M, Cohen M, Irazuzta JE, Kumar R, Kirton C, Brundler MA, Evans CA, Wilson JA, Raffeeq P, Azaz A, et al. Fulminant pertussis: a multi-center study with new insights into the clinico-pathological mechanisms. Pediatr Pulmonol. 2009:44(10):970-80.

27. Rowlands HE, Goldman AP, Harrington K, Karimova A, Brierley J, Cross N, Skellett S, Peters MJ. Impact of rapid leukodepletion on the outcome of severe clinical pertussis in young infants. Pediatrics. 2010;126(4):e816-27.

28. Kundrat SL, Wolek TL, Rowe-Telow M. Malignant pertussis in the pediatric intensive care unit. Dimens Crit Care Nurs. 2010;29(1):1-5.

29. Kuperman A, Hoffmann Y, Glikman D, Dabbah H, Zonis Z. Severe pertussis and hyperleukocytosis: is it time to change for exchange? Transfusion. 2014; 54(6):1630-3.

30. Grzeszczak MJ, Churchwell KB, Edwards KM, Pietsch J. Leukopheresis therapy for severe infantile pertussis with myocardial and pulmonary failure. Pediatr Crit Care Med. 2006;7(6):580-2.

31. De Berry BB, Lynch JE, Chung DH, Zwischenberger JB. Pertussis with severe pulmonary hypertension and leukocytosis treated with extracorporeal membrane oxygenation. Pediatr Surg Int. 2005;21(8):692-4.

32. Halasa NB, Barr FE, Johnson JE, Edwards KM. Fatal pulmonary hypertension associated with pertussis in infants: does extracorporeal membrane oxygenation have a role? Pediatrics. 2003;112(6 Pt 1):1274-8.

33. Chong CY, Yung CF, Tan NW, Acharyya S, Thoon KC. Risk factors of ICU or high dependency requirements amongst hospitalized pediatric pertussis cases: a 10 year retrospective series, Singapore. Vaccine. 2017;35(47):6422-8.

34. Vizzotti C, Juarez MV, Bergel E, Romanin V, Califano G, Sagradini S, Rancano C, Aquino A, Libster R, Polack FP, et al. Impact of a maternal immunization program against pertussis in a developing country. Vaccine. 2016;34(50): 6223-8.

35. Amirthalingam G, Campbell H, Ribeiro S, Fry NK, Ramsay M, Miller E, Andrews N. Sustained effectiveness of the maternal pertussis immunization program in England 3 years following introduction. Clin Infect Dis. 2016; 63(suppl 4):S236-s243.

36. (CDC). CfDCaP. Updated recommendations for use of tetanus toxoid, reduced diphtheria toxoid and acellular pertussis vaccine (Tdap) in pregnant women and persons who have or anticipate having close contact with an infant aged $<12$ months --- advisory committee on immunization practices (ACIP), 2011. MMWR Morb Mortal Wkly Rep. 2011;60(41):1424-6.

37. Walls T, Graham P, Petousis-Harris H, Hill L, Austin N. Infant outcomes after exposure to Tdap vaccine in pregnancy: an observational study. BMJ Open. 2016;6(1):e009536

38. Abu-Raya B, Maertens K, Edwards KM, Omer SB, Englund JA, Flanagan KL, Snape MD, Amirthalingam G, Leuridan E, Damme PV, et al. Global Perspectives on Immunization During Pregnancy and Priorities for Future Research and Development: An International Consensus Statement. Front Immunol. 2020;11:1282.

39. Zheteyeva YA, Moro PL, Tepper NK, Rasmussen SA, Barash FE, Revzina NV, Kissin D, Lewis PW, Yue $X$, Haber $P$, et al. Adverse event reports after tetanus toxoid, reduced diphtheria toxoid, and acellular pertussis vaccines in pregnant women. Am J Obstet Gynecol. 2012;207(1):59.e51-7.

40. Kharbanda EO, Vazquez-Benitez G, Lipkind HS, Klein NP, Cheetham TC, Naleway AL, Lee GM, Hambidge S, Jackson ML, Omer SB, et al. Maternal Tdap vaccination: coverage and acute safety outcomes in the vaccine safety datalink, 2007-2013. Vaccine. 2016;34(7):968-73.

41. Donegan K, King B, Bryan P. Safety of pertussis vaccination in pregnant women in UK: observational study. Bmj. 2014;349:94219.

\section{Publisher's Note}

Springer Nature remains neutral with regard to jurisdictional claims in published maps and institutional affiliations. 